\title{
Synthesis of Carbon Microparticles from Red Dragon Fruit (Hylocereus undatus) Peel Waste and Their Adsorption Isotherm Characteristics
}

\author{
Asep Bayu Dani Nandiyanto'*, Rina Maryanti' , Meli Fiandini', Risti Ragadhita', Dian Usdiyana', \\ Sri Anggraeni', Wafa Raihanah Arwa', Abdulkareem Sh. Mahdi Al-Obaidi \\ 'Universitas Pendidikan Indonesia, Jl. Dr. Setiabudhi no 229 Bandung 40154, Indonesia. \\ ${ }^{2}$ School of Computer Science and Engineering, Taylor's University, No.1 \\ Jalan SS 15/8 47500 Subang Jaya, Selangor DE, Malaysia \\ *Corresponding author email: nandiyanto@upi.edu
}

Received May 07, 2020; Accepted September 18, 2020; Available online November 20, 2020

\begin{abstract}
This study aims to demonstrate the preparation of carbon microparticles obtained from red dragon fruit peel waste and their adsorption isotherm characteristics. The carbon microparticles were prepared by combining carbonization (at $250^{\circ} \mathrm{C}$ ) and saw-milling process, and to get carbon microparticles with a specific size, sieve analysis was used. The adsorption isotherm was done by testing the adsorption ability of carbon microparticles with a specific size into curcumin solution in the batch-type reactor. The adsorption results were then compared to several standard isotherm models (i.e., Langmuir, Freundlich, Temkin, and Dubinin-Radushkevich models) for understanding what phenomena happen during the adsorption process. The adsorption analysis was also confirmed by testing several sizes of the carbon microparticles to predict the proposal mechanism in the adsorption process. The analysis results showed that the multilayer adsorption process occurs for all sizes in the micrometer range, and the process involves physical interactions between adsorbate and surface of adsorbent. The existence of multilayers is due to the possibility in the existence of porous structure in the carbon microparticles. This study is important for giving an alternative solution for reusable organic waste as well as supporting the fundamental researches in the further applications of carbon particles as catalyst and adsorbent.
\end{abstract}

Keywords: Adsorption isotherm; carbon; distribution particle; red dragon fruit peel; education

\section{INTRODUCTION}

Carbon is one of the most abundant organic materials in nature. The importance of carbon material can be found as a constituent of organism's structure and its stable nature compared to other materials (Jansa \& Treseder, 2017). The abundance of carbon relates to the diversity of compounds and their ability to form polymers such as carbohydrates, lipids, proteins, and nucleic acids (Jawad, Kadhum, \& Ngoh, 2018). Generally, carbon is found from organic and inorganic sources. The source of organic carbon comes from petroleum, peat rock, coal, and decomposed organic matter (the remains of organisms such as plants, animals, and waste products in the environment from agricultural waste). Carbon in inorganic sources comes from limestone, dolomite, carbon dioxide, and marble (Jansa \& Treseder, 2017; Jawad, Kadhum, \& Ngoh, 2018).

Carbon has extremely good properties such as large surface area, high mesopore volume, and high electrostatic charge on the surface. The extreme characteristics make carbon widely applied in various fields. In the industrial sector, carbon is applied as adsorbents, electroplating purifications, radioactive gas filters, a gas purifications, absorbent odors, rubber fillers, and catalysts (Hu, Jia, Cheng, \& Sun, 2019).

Many studies have reported the successful production of carbon (Riyanti et al., 2018). One of the best sources is from agricultural waste, such orange peel (Boumediene, Benaissa, George, Molina \& Merlin, 2015), manga peel (Jawad, Mamat, Abdullah, \& Ismail, 2017), durian peel (Annadurai, Juang, \& Lee, 2002), jackfruit peel (Hameed, 2009), and dragon fruit peel (Haddadian, Shayandi, Abidin, Fakhrul, \& Ismail, 2013). Although many studies have shown the successful preparation of carbon from various agriculture wastes, fabrication carbon from red dragon fruit peel wastes and further applications (i.e., adsorbent, in food, drug and related application) is still rarely discussed. In fact, red dragon fruit peel waste has the potential to be used as a carbon raw material since it is commonly found as a domestic waste in tropical countries, such as Indonesia. Moreover, almost $30-35 \%$ of red dragon fruit peel dominates the part of fruit and contains organic components (i.e., cellulose, hemicellulose, and lignin) (Herbach, Stintzing \& Carle, 2005; Hashem \& Amin, 2016; Priyantha, Lim, \& Dahri, 2015). 
This study aims to demonstrate the synthesis of carbon microparticles obtained from red dragon fruit peel waste and their adsorption isotherm characteristics. The carbon microparticles were prepared by combining carbonization (at $250^{\circ} \mathrm{C}$ ) and saw-milling process. To get carbon microparticles with a specific size, sieve analysis was used. The adsorption isotherm was done by testing the adsorption ability of the prepared carbon microparticles with a specific size into curcumin solution in the batch reactor, and the results were compared to several standard isotherm models: Langmuir, Freundlich, Temkin, and DubininRadushkevich models. The results were also completed with the proposal mechanism in the adsorption process.

The first novelty in this study was the investigation of adsorption isotherm of carbon microparticles that were prepared from red dragon peel waste. Red dragon peel waste, as the carbon source (since it has high amount of organic components), has become issues in tropical countries. Dragon fruit is the fifth most imported tropical fruit from Asia exported to China after lychee, longan, banana, and mango, making it as one of the product commodities in the world. For example, Vietnam has reached exports of dragon fruits of 533 tons in 2017, and the majority of dragon fruit in the Chinese market is from Vietnam. Malaysia had 1641 ha for dragon fruit production in 2013 and produced of about 11000 tons. Indonesia is reported to use 4300 ha (mainly in Banyuwangi, East Java and East Kalimantan), and from the 2,300 ha in Banyuwangi, they harvested 117700 tons of dragon fruits. The Philippines uses 450 ha in 2018 with a total production of 1463 tons (Paull \& Chen, 2019). Usually, dragon fruit is consumed without its peel, while peel (about 35\% of the total weight of the fruit) is disposed without further considerations (Prasetyo, 2013). Calculating the number of harvesting rate per year and the amount of peel in the fruit, Indonesia has issues in the existence of dragon peel waste of reaching 82000 ton per year. In fact, when the peel wastes are decomposed, bad odor or smell can be created. Thus, understanding strategy for transforming peel waste into better products such as carbon material is important for solving issues in the boosting number of dragon fruit peel waste, especially in Indonesia. Although the conversion of dragon fruit into carbon material has been reported (Haddadian, Shayandi, Abidin, Fakhrul, \& Ismail, 2013; Priyantha, Lim, \& Dahri, 2015), analysis of adsorption isotherm is still limited.

The second novelty is to investigate the effect of sizes of carbon microparticles on the phenomena of adsorption process. Correlations of particle size and the number of adsorption sites have been welldocumented, however reports on predicting phenomena as a function of particle size are still limited. In fact, this information brings suggestions for supporting the fundamental researches in the application of carbon particles such as catalyst and adsorbent.

The third novelty is the employment of curcumin as a model of adsorbate. Curcumin has sizes of less than $1.4 \mathrm{~nm}$, which is ideal for evaluating adsorbentadsorbate interaction. Thus, the correlation model gained in this study will be fit and applicable for predicting adsorption process of other types of adsorptive, especially when facing organic molecules and dyes (since dyes become one of the environmental issues relating to textile industry).

The fourth novelty is the investigation of micrometer-sized adsorbent particles. Although most of the recent studies focused on the evaluation of nanoparticles, this study emphasized the evaluation of microparticles. The characteristics of micrometer-sized particles are unique, which are different from nanoparticles, bulk, and film materials. Micrometersized particles are easily settled and decanted spontaneously, making them separated easily after using, allowing them to be reusable, and promoting them for not contaminating the sample for analysis. This settling ability avoids the misleading measurement and giving precise evaluation and analysis. Thus, this is prospective for being used as a tool for evaluating phenomena in the surface area.

\section{EXPERIMENTAL SECTION}

\section{Experimental procedures}

In this study, red dragon fruit (Hylocereus undatus) peel waste (obtained from Bandung, Indonesia) was used as the carbon source. In short, to produce carbon particles, red dragon fruit peel waste was sliced, washed with water to remove impurities, dried to remove existence of water on the surface physically at $100^{\circ} \mathrm{C}$, and carbonized at $250^{\circ} \mathrm{C}$ for 8 hours to obtained carbon material using an electric furnace in the atmosphere condition.

Then, the prepared carbon material was put into a saw-milling process $(18,000 \mathrm{rpm})$ to transform it into powder form. Detailed information for the saw-milling apparatus is explained in our previous report (Nandiyanto, Andika, Aziz, \& Riza, 2018).

The saw-milled carbon was then washed by ultrapure water and centrifuged (TG16-WS; Model G19010115QS) at $11000 \mathrm{rpm}$ for 5 minutes to remove ionic salt. Washing and centrifugation processes were carried out several times until a clear filtrate was obtained. The washed carbon product was then dried at $100^{\circ} \mathrm{C}$ to remove water.

The size distribution of the prepared carbon particles was obtained using a sieve test (PT Rumah Publication Indonesia, Indonesia with various holes of $2000,1000,530,250,125,99,74,58,48 \mu \mathrm{m})$. The sieve test was also used for obtaining a specific size of the carbon product. The prepared carbon particles were also characterized using a Fourier Transform Infrared (FTIR-4600, Jasco Corp., Japan) and a Digital Microscope (BXAW-AX-BC, China) to analyze the 
chemical structure and particle morphology, respectively.

To examine the adsorption isotherm of carbon particles, batch type adsorption process was done. In short, the adsorption experiments were done by adding carbon particles with a specific size (i.e., 100, 125 and $200 \mu \mathrm{m}$ ) into $100 \mathrm{~mL}$ of curcumin solution (with concentration of 20,30, and $50 \mathrm{ppm}$ ). Detailed information for the curcumin solution preparation from turmeric (Curcuma Litonga; obtained from Bandung, Indonesia) is explained in our previous studies (Nandiyanto, 2020). During the adsorption process, mixed suspension containing carbon microparticles and curcumin solution was stirred at $11,000 \mathrm{rpm}$. The aliquot of the solution was taken, filtered (using a filter with a mean pore size of $200 \mathrm{~nm}$ ) at a specific time, and put into a Visible Spectroscope (Model 7205; JENWAY; Cole-Parmer; US; analyzed at maximum wavelength at a maximum wavelength in the range of between 280 and 600) for the measurement of curcumin concentration. The absorption results from the spectrophotometer were then plotted, normalized, and calculated using the Beer Law for getting the curcumin concentration. The obtained concentration was then compared with the standard isotherm adsorption models: Langmuir, Freundlich, Temkin, and Dubinin-Radushkevich.

\section{Definition of Adsorption Isotherm Models}

The adsorption can be predicted using the adsorption isotherm model, in which the model illustrates and estimates the process for the solute adsorbate being absorbed on the surface of adsorbent under equilibirium conditions at a constant temperature (Foo \& Hameed, 2010). For understanding the characteristics of adsorption, concentration of adsorbate in the solution is measured, replying how much amount of it on the surface of adsorbent. This process involves important parameters that have correlation to the physicochemical data of the adsorbent material. In addition, this adsorption isotherm does not only provide equilibrium data on the adsorption process but also it provides relevant information about the spontaneity and stability of adsorbents on the surface of adsorbates (Foo \& Hameed, 2010). Many adsorption isotherm models are available, and the most commonly used models in the adsorption process are Langmuir, Freundlich, Temkin, DubininRadushkevich, Brunauer, Emmet, and Teller isotherm models (Matouq, Jildeh, Qtaishat, Hindiyeh, \& Al Syouf, 2015).

The illustration of process in the adsorption process is presented in Figure 1. This figure describes the process in the monolayer and multilayer adsorptions, which are shown in Figures $1 \mathbf{a}$ and $\mathbf{b}$, respectively. This study used four types of adsorption isotherms (i.e., Langmuir, Freundlich, Temkin, and Dubinin-
Radushkevich models) for predicting the type of adsorption, in which the models are explained in the following. Detailed information for the models are explained in our previous study (Nandiyanto, 2020). For the Langmuir isotherm, we used the following correlation: $\frac{1}{q_{e}}=\frac{1}{q_{\max } K_{L}} \frac{1}{C_{e}}+\frac{1}{q_{\max }}$

where $K_{L}$ is the Langmuir adsorption constant, $C_{e}$ is the concentration of adsorbate under equilibrium conditions $(\mathrm{mg} / \mathrm{L}), q_{e}$ is the amount of adsorbate adsorbed per mass of adsorbent $(\mathrm{mg} / \mathrm{g})$, and $q_{\max }$ is the monolayer adsorbent capacity $(\mathrm{mg} / \mathrm{g})$. Then, the correlation is turned on separation factor $\left(R_{L}\right)$, which is obtained by $R_{L}=\frac{1}{1+K_{L} C_{e}}$

where $C_{0}$ is the initial concentration of adsorbate $(\mathrm{mg} / \mathrm{L}) . R_{L}$ value is to determine the adsorption process:

(i) $R_{L}>1$ means the unfavorable adsorption process (the desorption process happens).

(ii) $R_{L}=1$ is the linear adsorption (the adsorption process is affected by the amount and concentration of adsorbate).

(iii) $R_{L}=0$ means the irreversible adsorption process (the adsorption process fabulous).

(iv) If $0<R_{L}<1$, it means the favorable adsorption (the adsorption process occurs under certain conditions).

For the Freundlich isotherm, we used the following equation: $\log q_{e}=\log k_{f}+\frac{1}{n_{e}} \log C_{e}$

where $k_{f}$ is the Freundlich constants, $n$ is the linear degree for the adsorption and $1 / n$ is sorption intensity. The $n$ and $1 / n$ values are described:

(i) $n=1$ means the linear adsorption process (the adsorption process is affected by the amount and concentration of adsorbate).

(ii) $n>1$ means the physical adsorption process.

(iii) $\mathrm{n}<1$ means the chemical adsorption process.

(iv) $1 / n>1$ means the cooperative adsorption process (the interaction between adsorbate and adsorbent on the surface of carbon which is able to absorb other adsorbate molecules).

(v) If $0<1 / n<1$, it means favorable adsorption (the adsorption process occurs under certain conditions).

For the Temkin model, we used the following equation: $\quad q_{e}=\beta_{T} \ln A_{T}+\beta_{T} \ln C_{e}$

where $B_{T}$ is the adsorption heat constant. $B_{T}$ can be defined as $\beta_{T}=\frac{R . T}{b_{T}}$ where $T$ is the absolute

temperature, $R$ is the gas constant $(8.314 \mathrm{~J} / \mathrm{mol} . \mathrm{K})$, and $b_{T}$ is the constant associated with the heat of the adsorption. 


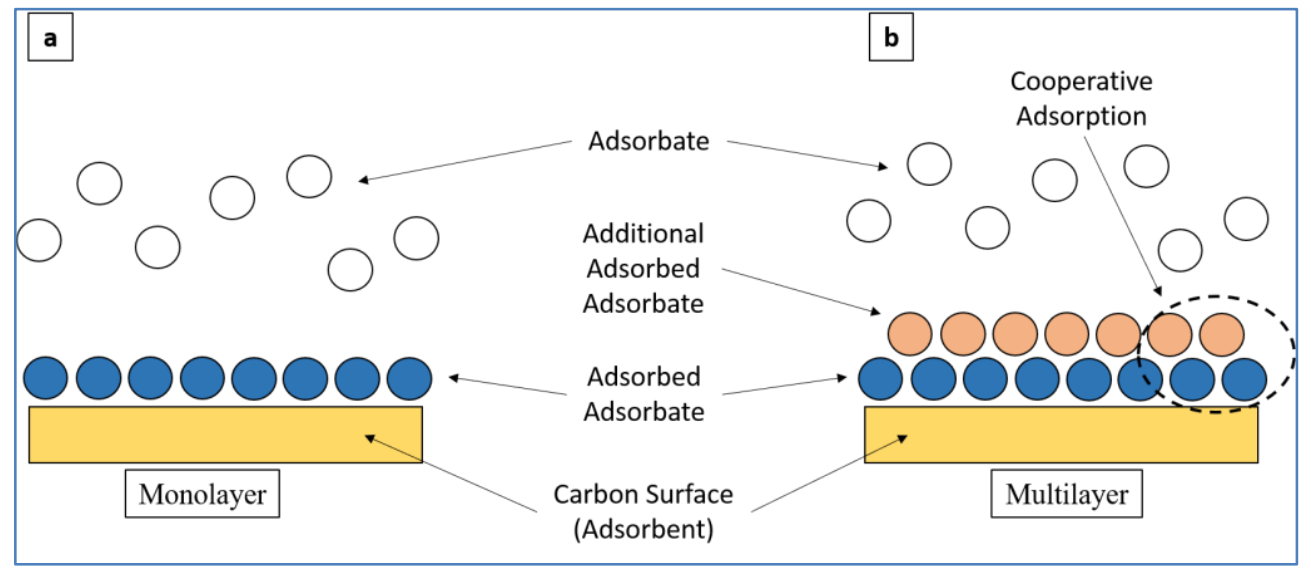

Figure 1. Illustration of monolayer (a) and multilayer (b) adsorption model

$A_{T}$ is the equilibrium binding constant in the state of equilibrium (L/min), depending on the adsorbate and the adsorbent maximum binding energy. If $B_{T}$ value is lower than $8 \mathrm{~kJ} / \mathrm{mol}$, the adsorption is done physically.

For the Dubinin-Radushkevich isotherm, we used the following correlation: $\ln q_{e}=\ln q_{m}-\left(\beta \varepsilon^{2}\right)$

where $\varepsilon$ is the Polanyi potential. The $\varepsilon$ value can be

$$
\text { obtained using: } \begin{gathered}
\varepsilon=R \cdot T \cdot \ln \left[1+\frac{1}{C_{e}}\right] \\
E=\frac{1}{\sqrt{2 \beta}}
\end{gathered}
$$

where $B$ is the Dubinin-Radushkevich isotherm model constant. $E$ is the mean free energy of adsorption, determining the type of adsorption:

(i) $E<8 \mathrm{~kJ} / \mathrm{mol}$ means the physical adsorption.

(ii) $E>8 \mathrm{~kJ} / \mathrm{mol}$ means the chemical adsorption.

The adsorption efficiency is measured by comparing the adsorption data with these models by matching the curves and equations using:

$$
\% E=\left(\frac{C_{o}-C_{e}}{C_{o}}\right)
$$

where $\% E$ is the efficiency of adsorption.

\section{RESULTS AND DISCUSSION}

Figure 2 shows the thermal analysis of the red dragon fruit peel. This study evaluated effects of heating time at a specific temperature on the formation of carbon microparticles. The analysis was done by putting $1 \mathrm{~g}$ of red dragon fruit peel on the electrical furnace at 110, 150, 200, 250, 300, and $400^{\circ} \mathrm{C}$. The mass decreased when applying temperature. The longer holding time results in the more loses in mass. However, too long holding time is not effective to the obtainment of more loses of mass. The higher temperature gives impact to the more loses in the material.

When the dragon fruit peel heated at $110^{\circ} \mathrm{C}$, the mass loses reached $94 \%$, in which this is due to the evaporation of some water component and the decomposition of fragile organic components. This is in line with previous reports that the water content in the Indonesian dragon fruit peel is about 94\% (Yati, Ladeska, \& Wirman, 2017).

Further additional higher temperature results in the more gradual decrement of mass. The final percentages of masses were $6.20 ; 5.90 ; 3.60 ; 2.52$; and $1.28 \%$ when heating at temperatures of 150,200 , 250,300 , and $400^{\circ} \mathrm{C}$, respectively. The best condition to get the conversion of organic components into carbon is $250^{\circ} \mathrm{C}$, verified by the appearance of black powder after the burning process. This temperature is enough for converting cellulose and hemicellulose into carbon material (Tomczyk, Sokołowska, \& Boguta, 2020). Further uses of higher temperatures are not effective since it requires more energy for heating process and produces lower amount of carbon component (some carbon components were reconvert into $\mathrm{CO}$ and $\mathrm{CO}_{2}$ gases) (Nandiyanto et al., 2017).

To ensure the successful formation of carbon material from the thermal decomposition of red dragon fruit peel waste, FTIR analysis of the samples heated at various temperatures was conducted (Figure 3). The results showed that the transformation in the chemical bonding was found, in which the formation of carbon is started from temperature of $250^{\circ} \mathrm{C}$. To further analysis, the heated red dragon fruit peel was milled, washed, and separated based on particle size. Then, the carbon samples based on the particle size was re-analyzed using FTIR (Figure 4).

Figure 4 shows the FTIR analysis of the carbon particles with sizes of 100, 125, and $200 \mu \mathrm{m}$. As a standard comparison of the carbon material, figure was supported by carbon analysis data extracted from from Nandiyanto et al. (2017) and Nandiyanto (2019). The FTIR peaks and patterns of all samples were identical, showing that all samples were carbon. Several peaks were detected and fit for the carbon material. The vibration peak at wavelength of 1011 $1615 \mathrm{~cm}^{-1}$ is aliphatic compounds. The vibration peak at wavelength of $3388-33900 \mathrm{~cm}^{-1}$ shows the presence of internally bonded $\mathrm{OH}$ stretch (Nandiyanto, Oktiani \& Ragadhita, 2019). This stretch is possibly occurs because of the carboxyl group 
$(\mathrm{O}=\mathrm{C}-\mathrm{OH}$ or $-\mathrm{OH})$ that is contained in the organic compound in red dragon fruit peel (Moosa, Ridha, \& Abdullha, 2015).

The FTIR was used only to evaluate the similarity of functional groups existing in the carbon microparticles with various sizes. This similarity analysis is important to confirm the reliability of the present process for converting dragon peel waste into carbon in the specific size. The similar functional groups in the carbon microparticles are important to ensure the precise measurement for understanding the effect of particle size on the adsorption phenomena. Indeed, to confirm the detailed elemental structure, additional characterizations such as X-ray diffraction and X-ray fluorescence is important, in which these will be done in our future work.

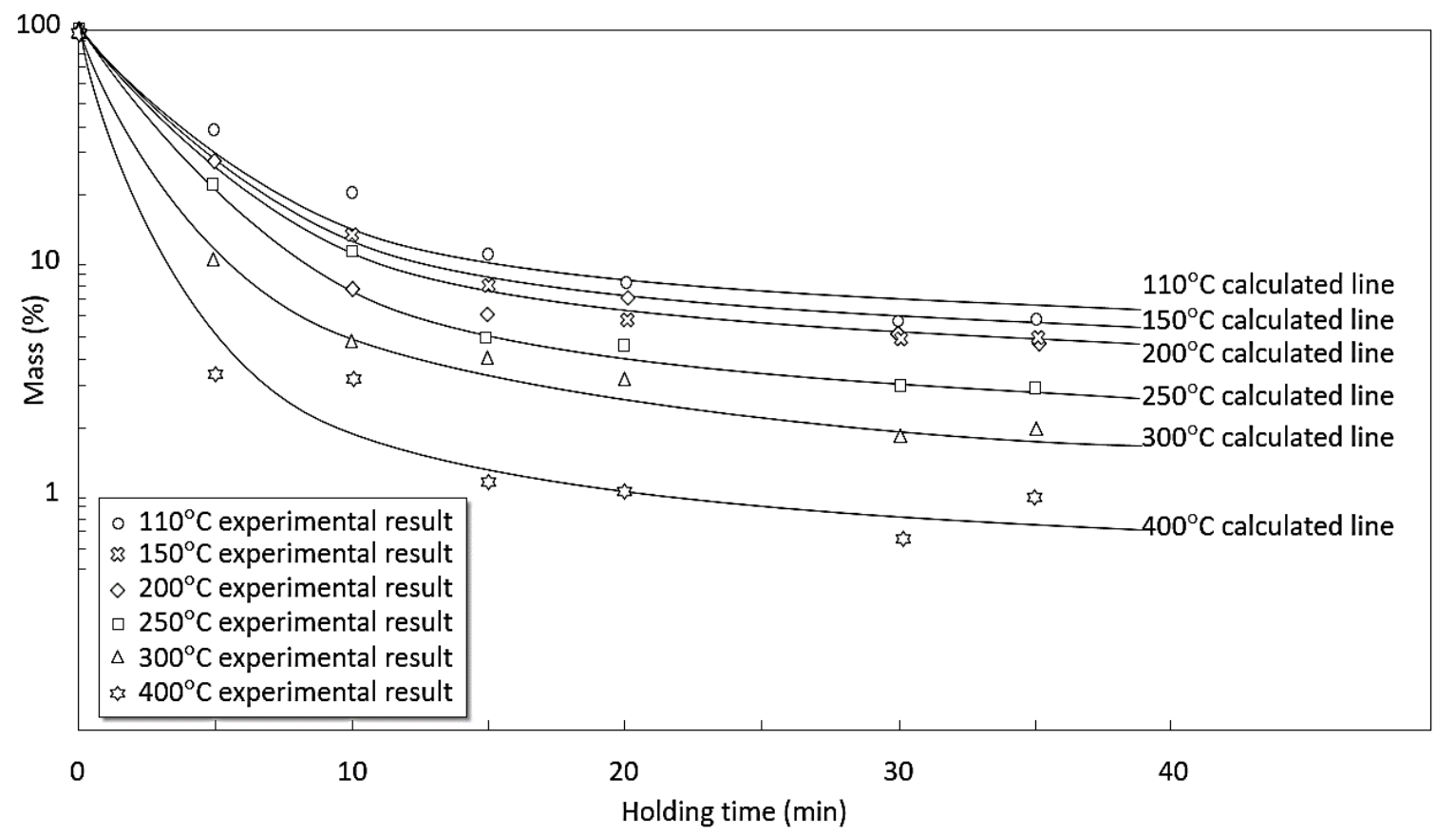

Figure 2. Mass decomposition of red dragon fruit peel as a function of heating temperature and heating holding time.

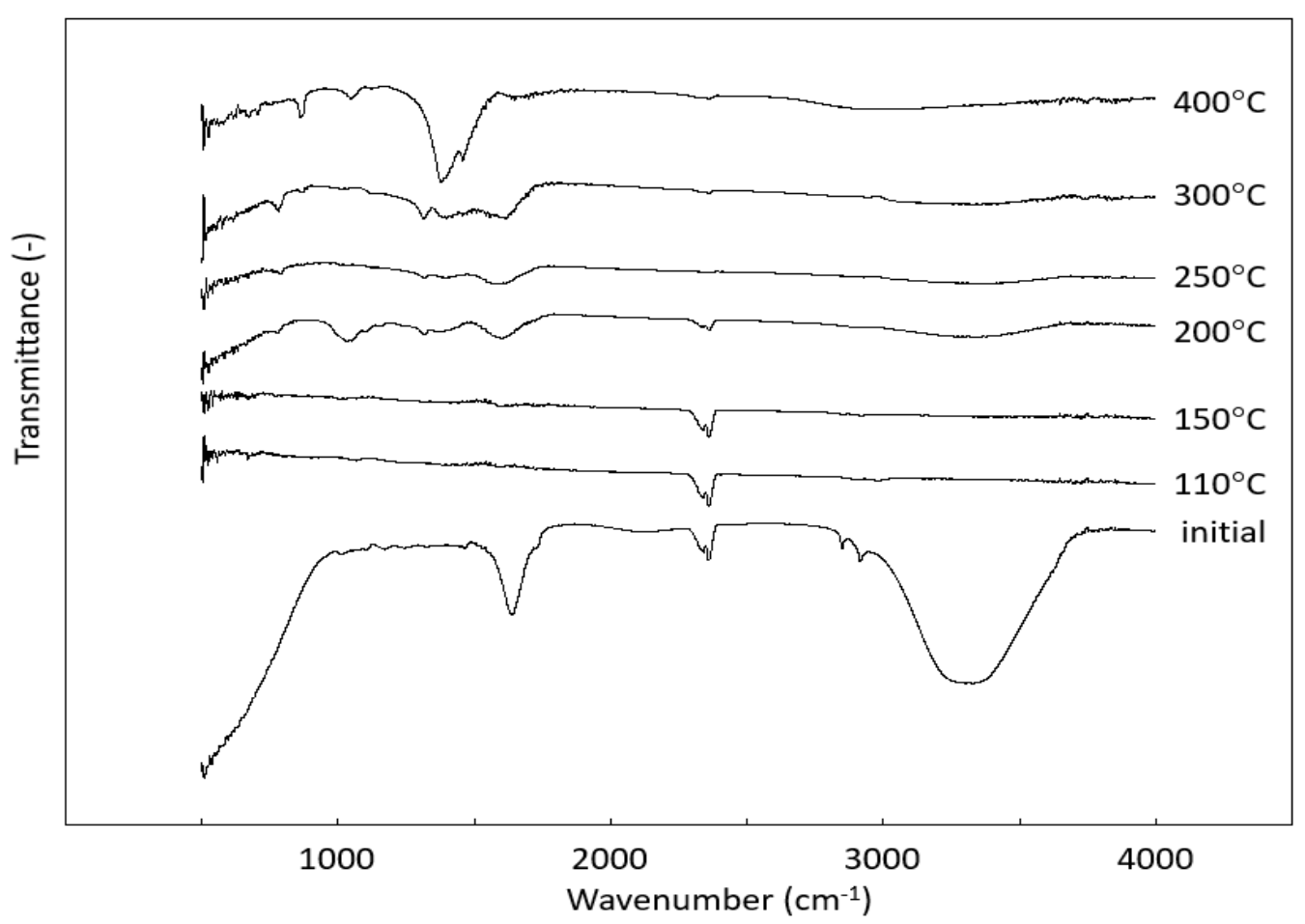

Figure 3. FTIR analysis of red dragon fruit peel waste heated at various temperatures. 


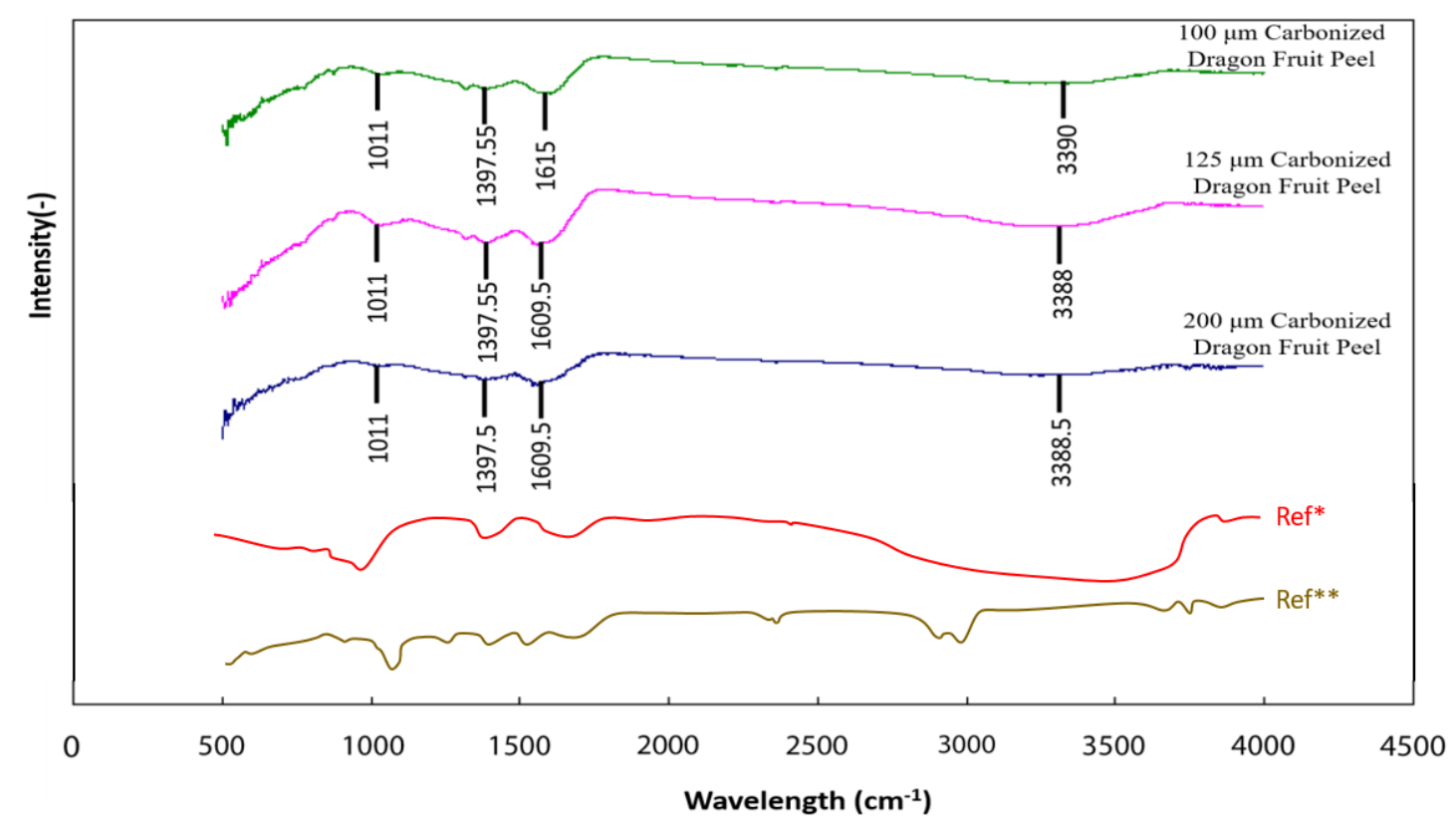

Figure 4. The FTIR analysis results of carbon particles with various sizes. Ref* and Ref** are data extracted from Nandiyanto et al. (2017) and Nandiyanto (2019), respectively.

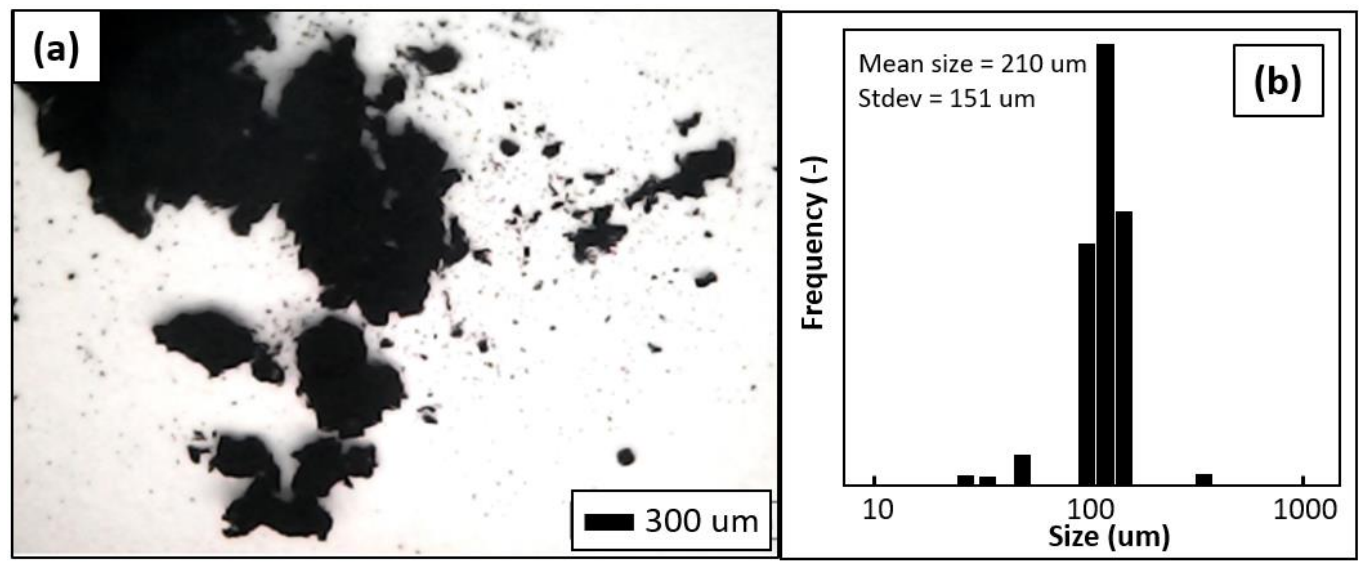

Figure 5. The microscope analysis image of carbon microparticles (a) and their size distribution (b)

The microscope analysis of carbon particles is shown in Figure 5a. The analysis results showed that the carbon microparticles have heterogeneous surface and agglomerated particles. To confirm the particle size distribution, sieve test analysis was used, and the results are depicted in Figure 5b. The analysis showed that sizes of carbon particles are in the range of 20 $270 \mu \mathrm{m}$. The mean of particle size is $210 \mu \mathrm{m}$, and the size of carbon is mostly in the range of 95-210 $\mu \mathrm{m}$. Since the particle sizes are in the micrometer range, the optical microscope is enough to distinguish the outer size of the particles. However, to ensure the structure on the particles, additional characterizations are required, such as scanning electron microscope, in which this will be done in our future work.

Figure 6 shows the adsorption analysis of the four isotherm models. Listing the value of linearization plot $\left(R^{2}\right)$ shows the compatibility of the isotherm, sequentially following Dubinin-Radushkevich Langmuir $>$ Temkin $>$ Freundlich. Detailed analysis results are shown in Table 1. Analysis of the Langmuir isotherm model is presented in Figure 6a. The Langmuir isotherm model describes the characteristics of monolayer adsorption. The values of $Q_{\max }$ and $K_{L}$ are shown in Table 1. The correlation coefficient $R^{2}$ of Langmuir is greater than that of the Freundlich and the Temkin, in which it is the second best fit model in the plotting $1 / Q_{e}$ versus $1 / C_{e}$ (Equation (1)). The plotted linearization results in a straight line of slope $1 / Q_{\max }$. The $R_{L}$ value obtained is $0<R_{L}<1$, indicating that the adsorption is favorable. Favorable process is the adsorption process under certain conditions, in which there is almost no desorption and no effects from the amount and concentration of adsorbate on the adsorption process. Analysis of the Freundlich isotherm model is shown in Figure 6b. The Freundlich isotherm model describe the characteristics of multilayer adsorption. The sorption intensity analysis as $1 / n$ value replies the process is favorable (the value is $0<1 / n<1$ as shown in Table 1). This is in a good 
agreement with the analysis of Langmuir isotherm model for the favorable adsorption in Figure 6a. The value of $n>1$ obtained in the Freundlich also supports the existence of physical adsorption process. Figure $6 c$ shows the analysis of the Temkin isotherm model. The Temkin isotherm model concluded that the adsorption energy values $\left(\beta_{T}\right)$ is less than $8 \mathrm{~kJ} / \mathrm{mol}$, informing the occurrence of physical adsorption, in which this is in a good agreement with Freundlich model in Figure 6b.Figure $6 \mathrm{~d}$ shows the results from the analysis of the Dubinin-Radushkevich isotherm model. In this study, the Dubinin-Radushkevich has the highest correlation coefficient $R^{2}$, informing that this model is the most suitable adsorption process for explaining what phenomena happen during the adsorption of curcumin by carbon microparticles. The DubininRadushkevich isotherm model (E value shown in Table 1 is less than $8 \mathrm{~kJ} / \mathrm{mol}$ ) described the physical adsorption process under heterogeneous surfaces, in which this is in a good agreement with Freundlich and Temkin isotherm models.

The results of this study presented that particle sizes of $125 \mu \mathrm{m}$ has the best adsorption efficiency value compared to sizes of 100 and $200 \mu \mathrm{m}$ (see Table 1). Particle size has an effect on the adsorption process. The smaller particle size relates to the greater surface area, allowing greater adsorption capacity (Engates \& Shipley, 2011). This supports the results of the
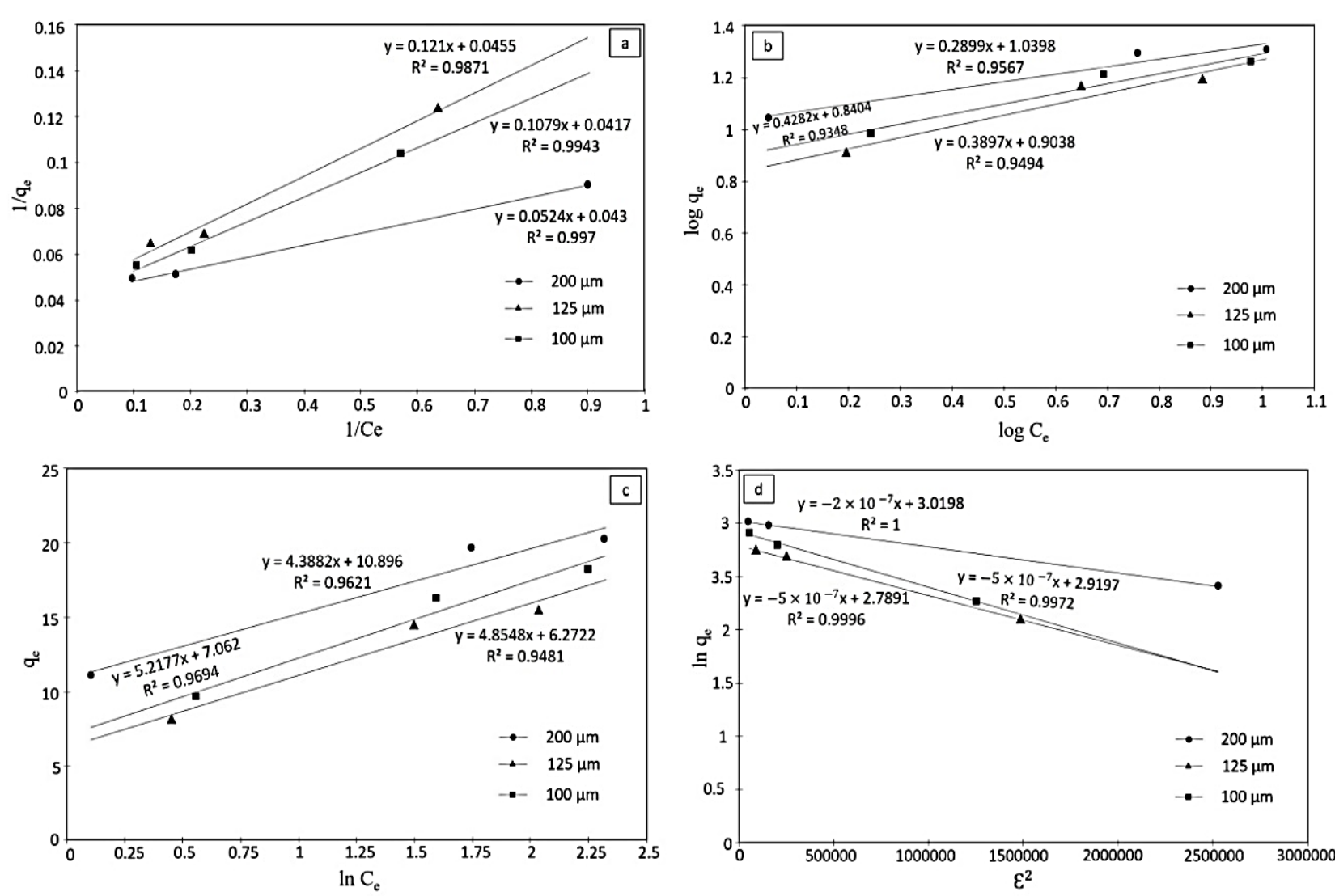

adsorption of $125-\mu \mathrm{m}$ particles, having better adsorption efficiency compared to that of $200-\mu \mathrm{m}$ particles. However, when using 100- $\mu$ m particles, the adsorption process was not optimal, in which this is because the smaller particles are easily agglomerated, deteriorating the adsorption process (Michelsen et al., 2007; Nabavi et al., 2016).

Illustration of the adsorption process using carbon microparticles (as the adsorbent) and curcumin (as the adsorbate) is depicted in Figure 7. DubininRadushkevich model as the most fitted models based on $R^{2}$ value showed that the interaction between adsorbate molecule and surface of adsorbent is conducted in multilayer adsorption involving physical process on the heterogeneous surfaces. This physical process is confirmed by all four models. The analyses from Freundlich (from the values of $n$ and $1 / n$ ) and Langmuir (from the value of $1 / n$ ) showed that the adsorption is favorable, informing the adsorption process is prefer done than the desorption process (Chaudhry, Zaidi \& Siddiqui, 2017). In general, it can be concluded that during the adsorption process, physical interactions between adsorbate and surface of adsorbent occur. This interaction happen when the adsorbate molecules attach directly to the surface of the adsorbent, forming adsorption layer (Jang, Yoo, Choi, Park \& Kan, 2018).

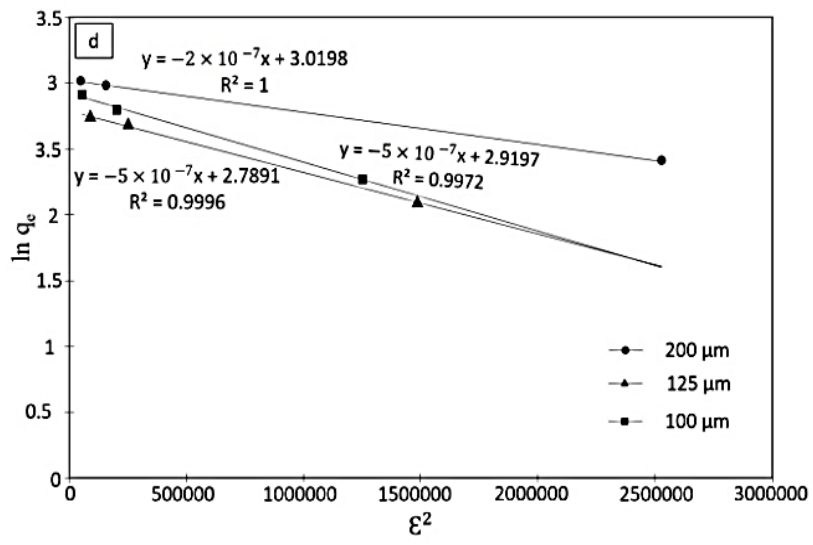

Figure 6. Plotting adsorption analysis using several adsorption isotherm models: (a) Langmuir, (b) Freundlich, (c) Temkin, and (d) Dubinin-Radushkevich. The figure was also completed with regression linear results and $R^{2}$ values. 
Table 1. Parameters of Langmuir, Freundlich, Temkin, and Dubinin-Radushkevich adsorption isotherm models obtained in this study

\begin{tabular}{|c|c|c|c|c|c|}
\hline \multirow[t]{2}{*}{ Model } & \multirow[t]{2}{*}{ Parameter } & \multicolumn{3}{|c|}{ Particle Size $(\mu \mathrm{m})$} & \multirow[t]{2}{*}{ Note } \\
\hline & & 250 & 125 & 99 & \\
\hline \multirow[t]{5}{*}{$\underset{r}{\text { Langmui }}$} & $K_{L}(\mathrm{~L} / \mathrm{mg})$ & 0.82 & 0.376 & 0.39 & $\begin{array}{l}\text { Relatively small } K_{L} \text { values, indicating } \\
\text { that there is a weak interaction } \\
\text { between adsorbate and adsorbent. }\end{array}$ \\
\hline & $q_{\max }(\mathrm{mg} / \mathrm{g})$ & 23.26 & 21.98 & 23.98 & $\begin{array}{l}\text { Representing the maximum } \\
\text { adsorption capacity. }\end{array}$ \\
\hline & $R_{L}$ & 0.026 & 0.056 & 0.054 & $0<R_{L}<1$, favorable Adsorption. \\
\hline & $R^{2}$ & 0.9970 & 0.9871 & 0.9943 & The correlation coefficients. \\
\hline & $\% E(\%)$ & 58.93 & 81.20 & 77.51 & Percentage of adsorption efficiency. \\
\hline \multirow[t]{3}{*}{$\begin{array}{l}\text { Freundli } \\
\text { ch }\end{array}$} & $k_{f}(\mathrm{mg} / \mathrm{g})$ & 10.96 & 6.92 & 8.01 & $\begin{array}{l}\text { The adsorption capacity of the } \\
\text { adsorbent. }\end{array}$ \\
\hline & $\begin{array}{l}1 / n \\
n\end{array}$ & $\begin{array}{c}0.2899 \\
3.45\end{array}$ & $\begin{array}{c}0.4282 \\
2.34\end{array}$ & $\begin{array}{c}0.3897 \\
2.57\end{array}$ & $\begin{array}{l}0<1 / n<1 \text { Favorable Adsorption. } \\
n>1 \text {, Physical Adsorption. }\end{array}$ \\
\hline & $R^{2}$ & 0.9567 & 0.9348 & 0.9494 & The correlation coefficients. \\
\hline \multirow[t]{2}{*}{ Temkin } & $B_{T}(\mathrm{~kJ} / \mathrm{mol})$ & 0.5646 & 0.4748 & 0.5103 & $B_{T}<8 \mathrm{~kJ} / \mathrm{mol}$, Physical Adsorption. \\
\hline & $R^{2}$ & 0.9621 & 0.9694 & 0.9481 & The correlation coefficients. \\
\hline \multirow{2}{*}{$\begin{array}{l}\text { Dubinin- } \\
\text { Radushk } \\
\text { evich }\end{array}$} & $q_{s}(\mathrm{mg} / \mathrm{g})$ & 3.0198 & 2.7891 & 2.9197 & $\begin{array}{l}\text { Theoretical isotherm saturation } \\
\text { capacity. }\end{array}$ \\
\hline & $\begin{array}{l}E(\mathrm{~kJ} / \mathrm{mol}) \\
R^{2}\end{array}$ & $\begin{array}{c}1.581 \\
0.9999\end{array}$ & $\begin{array}{c}1 \\
0.9996\end{array}$ & $\begin{array}{c}1 \\
0.9972\end{array}$ & $\begin{array}{l}E<8 \mathrm{~kJ} / \mathrm{mol} \text {, Physical Adsorption. } \\
\text { The correlation coefficients. }\end{array}$ \\
\hline
\end{tabular}

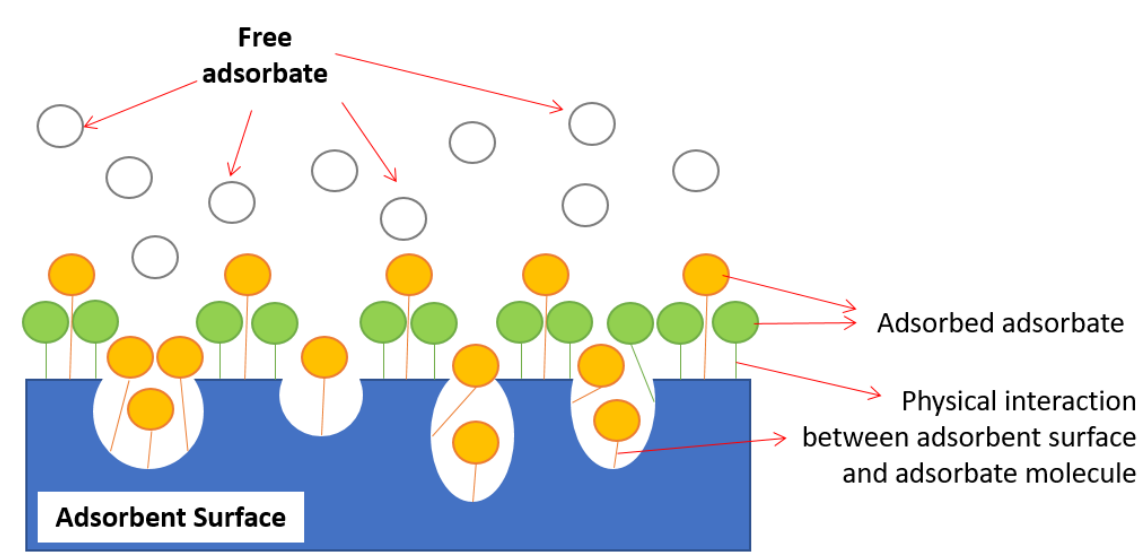

Figure 7. Proposal illustration of adsorbent process using carbon (as the adsorbent) and curcumin (as the adsorbate)

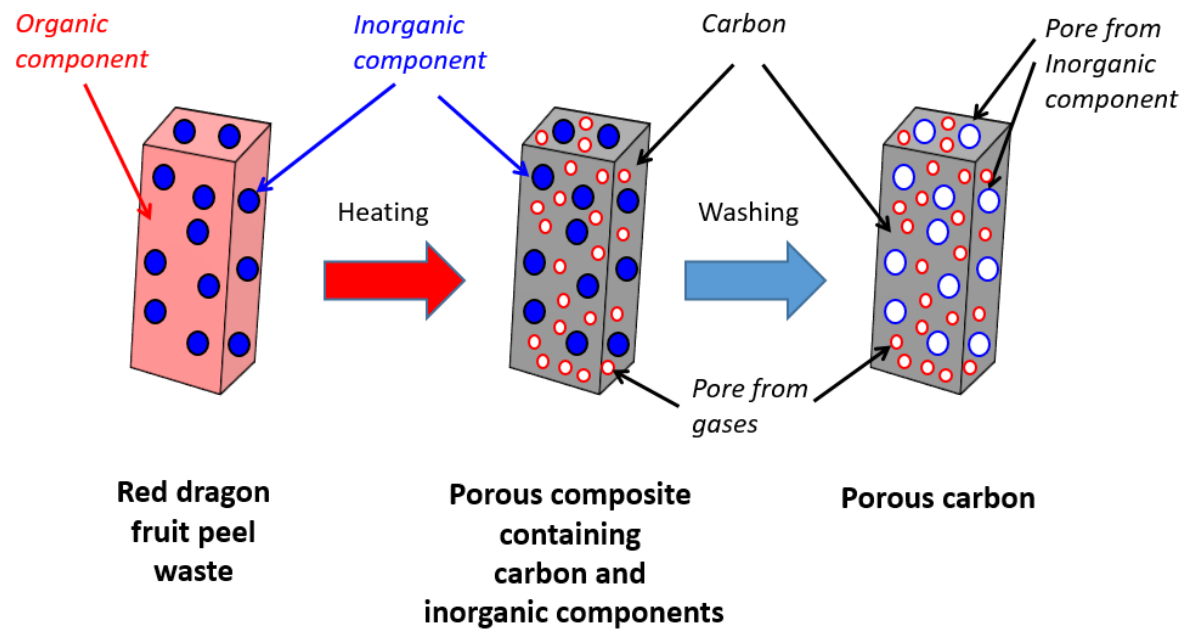

Figure 8. Proposal illustration of the formation of carbon with pores from red dragon fruit peel waste 
The Freundlich model also confirmed using $1 / n$ value that there is no cooperative adsorption. Thus, all adsorbate molecules directly contact to the surface of adsorbent. The main reason for the possible formation of multilayer is due to the additional structure on the surface, such as porous structure, in which this has been confirmed in our previous work (Nandiyanto et al., 2017). This is possibly happening since the formation of carbon is from red dragon fruit peel waste that contains some inorganic components (See Figure 8).

As shown in Figure 8, the carbonization process allows the formation of porous composite particles. Then, the washing process leads to the additional more porous structure in the material. The pores are formed due to several phenomena:

(1) During carbonization process, cellulose-related components are converted into carbon. Some reduction processes of cellulose-related components result in the formation of $\mathrm{CO}$ and $\mathrm{CO}_{2}$ gases. The existence of gases govern in the carbon-carbon element interaction in the formation of carbon material. Then, the releases of gases results in the formation of porous particles.

(2) When the carbonization process occurs, the decomposition of cellulose-related components is followed by the reaction of non-carbon organic elements such as nitrogen, oxygen, and hydrogen. The non-carbon organic elements interact each other and some of them react with carbon. Several gases can be formed, such as $\mathrm{NOx}, \mathrm{N}_{2}, \mathrm{H}_{2} \mathrm{O}, \mathrm{CH}_{4}$ and volatile matter, $\mathrm{H}_{2}$, etc. The gases can occupy in the formation of carbon material. When they release, they remain porous structure.

(3) In addition, during the carbonization, the inorganic components in the biomassa mostly form metal oxides. When the composite is washed, some metal oxides diffuse and dilute, remaining additional porous structure.

The existence of porous structure must be confirmed by further analysis such as nitrogen sorption analysis, in which this will be done in our future work.

In addition, the values of $R^{2}$ for all models are almost the same, which are more than 0.95. The measured materials are the same but the parameters, such as $q_{\max }$ in the Langmuir, $k_{f}$ in the Freundlich, and $q_{s}$ in the Dubinin-Radushkevich, were different. The main reason is because of their models assumptions. The Langmuir isotherm assumes the process as a monolayer adsorption that occurs on homogeneous surfaces; Thus, the value of $q_{\max }$ in the Langmuir is the maximum number of adsorbate area on the monolayer adsorbent in homogeneous surface. This is different from the value of $k_{f}$ in the Freundlich and $q_{s}$ in the Dubinin-Radushkevich isotherm that is generally applied for heterogeneous surfaces. This reason make the value of $q_{s}$ and $k_{f}$ are lower than that of $q_{\max }$.
Dubinin-Radushkevich also added the Gaussian energy distribution and Van der Waals force in the pore into the calculation, which is more complex assumptions than the Freundlich models. As a consequence, the value of $q_{s}$ is lower than that of $k_{f}$ since the size of the adsorbate interfere the adsorption process. However, to confirm the realistic value of adsorption capacity, additional analysis such as nitrogen sorption measurement is required, in which this will be done in our future work.

\section{CONCLUSIONS}

The demonstration in the preparation of carbon microparticles from red dragon fruit and their adsorption isotherm characterisctics has been successfully reported. Carbon microparticles were successfully prepared by carbonization and sawmilling process. The carbon microparticles with a specific size can be obtained by applying sieve test. Based on the results of plotting data on the Langmuir, Freundlich, Temkin, and Dubinin-Radushkevich adsorption models, the equilibrium data showed that the best fitted model is the Dubinin-Radushkevich isotherm model. The analysis results showed that the multilayer adsorption process occurs for all sizes in the micrometer range, and the process involves physical interactions between adsorbate and surface of adsorbent. The existence of multilayers is due to the possibility in the existence of porous structure in the carbon microparticles. This study is important for supporting the fundamental researches in the application of carbon particles such as catalyst and adsorbent.

\section{ACKNOWLEDGEMENTS}

This study acknowledged RISTEK BRIN for Grantin-aid Penelitian Terapan Unggulan Perguruan Tinggi (PTUPT). We also acknowledged Bangdos, Universitas Pendidikan Indonesia. We thank to Muhammad Raihan Fadillah, Nabila Nurul Annisa Az Zahra, and Imam Imadudin for assisting this research.

\section{REFERENCES}

Annadurai, G., Juang, R.S., \& Lee, D.J. (2002). Use of cellulose-based wastes for adsorption of dyes from aqueous solutions. Journal of hazardous materials, 92(3), 63-274.

Boumediene, M., Benaïssa, H., George, B., Molina, S., \& Merlin, A. (2015). Characterization of two cellulosic waste materials (orange and almond peels) and their use for the removal of methylene blue from aqueous solutions. Maderas. Ciencia y tecnología, 17(1), 69-84.

Chaudhry, S.A., Zaidi, Z., \& Siddiqui, S.I. (2017). Isotherm, kinetic and thermodynamics of arsenic adsorption onto Iron-Zirconium Binary Oxide-Coated Sand (IZBOCS): Modelling and process optimization. Journal of Molecular Liquids, 229(2017), 230-240. 
Engates, K.E., \& Shipley, H.J. (2011). Adsorption of $\mathrm{Pb}, \mathrm{Cd}, \mathrm{Cu}, \mathrm{Zn}$, and $\mathrm{Ni}$ to titanium dioxide nanoparticles: effect of particle size, solid concentration, and exhaustion. Environmental Science and Pollution Research, 18(3), 386395.

Foo, K.Y., \& Hameed, B.H. (2010). Insights into the modeling of isotherm adsorption systems. Chemical Engineering Journal, 156(1), 2-10.

Haddadian, Z., Shavandi, M.A., Abidin, Z.Z., Fakhrulrazi, A., \& Ismail, M.H.S. (2013). Removal methyl orange from aqueous solutions using dragon fruit (Hylocereusundatus) foliage. Chemical Science Transactions, 2(3), 900-910.

Hameed, B.H. (2009) Removal of cationic dye from aqueous solution using jackfruit peel as nonconventional low-cost adsorbent. Journal of hazardous materials, 162(1), 344-350.

Hashem, F.S., \& Amin, M.S. (2016). Adsorption of methylene blue by activated carbon derived from various fruit peels. Desalination and Water Treatment, 57(47), 22573-22584.

Herbach, K.M., Stintzing, F.C., \& Carle, R. (2005). Identification of heat-induced degradation products from purified betanin, phyllocactin and hylocerenin by high-performance liquid chromatography/electrospray ionization mass spectrometry. Rapid Communications in Mass Spectrometry: An International Journal Devoted to the Rapid Dissemination of Up-to-the-Minute Research in Mass Spectrometry, 19(18), 26032616.

Hu, X., Jia, L., Cheng, J., \& Sun, Z. (2019). Magnetic ordered mesoporous carbon materials for adsorption of minocycline from aqueous solution: preparation, characterization and adsorption mechanism. Journal of Hazardous Materials, 362(2019), 1-8.

Jang, H.M., Yoo, S., Choi, Y.K., Park, S., \& Kan, E. (2018). Isotherm adsorption, kinetic modeling and mechanism of tetracycline on Pinus taedaderived activated biochar. Bioresource Technology, 259(2018), 24-31.

Jansa, J., \& Treseder, K.K. (2017). Introduction: mycorrhizas and the carbon cycle. In Mycorrhizal Mediation of Soil, 19(2017), 343355.

Jawad, A.H., Kadhum, A.M., \& Ngoh, Y.S. (2018). Applicability of dragon fruit (Hylocereus polyrhizus) peels as low-cost biosorbent for adsorption of methylene blue from aqueous solution: kinetics, equilibrium and thermodynamics studies. Desalination and Water Treatment, 109(2018), 231-240.

Jawad, A.H., Mamat, N.F.H., Abdullah, M.F., \& Ismail, K. (2017). Adsorption of methylene blue onto acid-treated mango peels: kinetic, equilibrium and thermodynamic study.
Desalination and Water Treatment, 59(2017), 210-219.

Matouq, M., Jildeh, N., Qtaishat, M., Hindiyeh, M., \& Al Syouf, M.Q. (2015). The adsorption kinetics and modeling for heavy metals removal from wastewater by Moringa pods. Journal of Environmental Chemical Engineering, 3(2), 775-784

Michelsen, H.A., Tivanski, A.V., Gilles, M.K., Van Poppel, L.H., Dansson, M.A., \& Buseck, P.R. (2007). Particle formation from pulsed laser irradiation of soot aggregates studied with a scanning mobility particle sizer, a transmission electron microscope, and a scanning transmission x-ray microscope. Applied optics, 46(6), 59-977.

Moosa, A.A., Ridha, A.M., \& Abdullha, I.N. (2015). Chromium ions removal from wastewater using carbon nanotubes. International Journal Innovative Research Sciences Enginering Technology, 4(2), 275-285.

Nabavi, S. A., Vladisavljević, G. T., Eguagie, E. M., Li, B., Georgiadou, S., \& Manović, V. (2016). Production of spherical mesoporous molecularly imprinted polymer particles containing tunable amine decorated nanocavities with $\mathrm{CO} 2$ molecule recognition properties. Chemical Engineering Journal, 306(2016), 214-225.

Nandiyanto, A. B. D. (2019). Amorphous porous carbon microparticles from lumbricus rubellus. Journal of Engineering Research, 7 (special issue October 2019), 13-20.

Nandiyanto, A. B. D. (2020). Isotherm Adsorption of Carbon Microparticles Prepared from Pumpkin (Cucurbita maxima) Seeds Using TwoParameter Monolayer Adsorption Models and Equations. Moroccan Journal of Chemistry, 8(3), 8-3.

Nandiyanto, A.B.D., Andika, R., Aziz, M., \& Riza, L.S. (2018). Working volume and milling time on the product size/morphology, product yield, and electricity consumption in the ball-milling process of organic material. Indonesian Journal of Science and Technology, 3(2), 82-94.

Nandiyanto, A.B.D., Oktiani, R., \& Ragadhita, R. (2019). How to Read and Interpret FTIR Spectroscope of Organic Material. Indonesian Journal of Science and Technology, 4(1), 97-118.

Nandiyanto, A.B.D., Putra, Z.A., Andika, R., Bilad, M.R., Kurniawan, T., Zulhijah, R., \& Hamidah, I. (2017). Porous activated carbon particles from rice straw waste and their adsorption properties. Journal of Engineering Science and Technology, 12, 1-11.

Paull, R. E., \& Chen, N. J. (2019). Overall dragon fruit production and global marketing. Retrieved from https://ap.fftc.org.tw/article/1596. 
Prasetyo, E. G. (2013). Rasio Jumlah Daging dan Kulit Buah pada Pembuatan Selai Buah Naga Merah (Hylocereus polyrhizus) Ditambah Rosela (Hibiscus sabdariffa L.) dan Kayu Manis (Cinnamomum Sp). Bachelor Thesis Universitas Jember.

Priyantha, N., Lim, L.B.L., \& Dahri, M. K. (2015). Dragon fruit skin as a potential biosorbent for the removal of methylene blue dye from aqueous solution. International Food Research Journal, 22(5), 2141-2148.

Riyanti, F., Hariani, P.L., Purwaningrum, W., Elfita, E., Damarril, S.S., \& Amelia, I. (2018). The synthesis of $\mathrm{MnFe} 2 \mathrm{O} 4$-activated carbon composite for removal of methyl red from aqueous solution. Molekul, 13(2), 123-132.

Tomczyk, A., Sokołowska, Z., \& Boguta, P. (2020). Biochar physicochemical properties: pyrolysis temperature and feedstock kind effects. Reviews in Environmental Science and Bio/Technology, $19,191-215$.

Yati, K., Ladeska, V., \& Wirman, A. P. (2017). Isolasi Pektin dari Kulit Buah Naga (Hylocereus polyrhizus) dan Pemanfaatannya sebagai Pengikat pada Sediaan Pasta Gigi. Media Farmasi, 14(1), 1-16. 